This is a pre-print version of the paper forthcoming in Communication, Information and Society. Do not post this document on any Web sites or distribute it on any mailing lists.

\title{
The Disability Divide in Internet Access and Use
}

\author{
Kerry Dobransky and Eszter Hargittai*
}

\begin{abstract}
The increasing spread of the Internet holds much potential for enhancing opportunities for people with disabilities. However, scarce evidence exists to suggest that people with disabilities are, in fact, participating in these new developments. Will the spread of information technologies (IT) increase equality by offering opportunities for people with disabilities? Or will a growing reliance on IT lead to more inequality by leaving behind certain portions of the population including people with disabilities? In this paper, we draw on nationally representative data about Americans' Internet uses to (1) identify the extent to which people with disabilities are embracing use of the Internet; (2) how their use of the Internet compares to the Internet uses of the rest of the population; (3) how having a disability relates to and interacts with other social statuses (e.g. socio-economic status, age, gender) with regard to Internet use; and (4) what explains these trends. We draw on representative data collected by the Bureau of Labor Statistics and the Census of the United States to answer these questions. We find that people with disabilities are less likely to live in households with computers, are less likely to use computers and are less likely to be online. However, once we control for socio-economic background, we find that people with hearing disabilities and those who have limited walking ability are not less likely to be Internet users. Our research enables a deeper understanding of both the use of the Internet by people with disabilities and the spread of new IT more generally.
\end{abstract}

Keywords: Internet use, disability, digital divide, digital inequality

*Please direct correspondence to Eszter Hargittai, 2240 Campus Dr. Evanston, IL 60208. Email: disabilitydivide06@webuse.org

Acknowledgements:

The authors would like to thank Jennifer Humensky for help with data management. Jeremy Freese and Peter Miller provided helpful suggestions. Hargittai acknowledges the support of the Northwestern University Communication Studies Department Research Fund. 


\section{INTRODUCTION}

It is well established that there is a gap, a "digital divide," within and between societies in the degree to which different groups have access to and use information and communications technologies (ICT) (DiMaggio et al. 2004b; Hargittai 2003; Lenhart et al. 2003; Norris 2001; van Dijk 2005; Warschauer 2003). In the United States, research has shown that some of the same statuses that serve to stratify society in general terms, e.g.., race and socio-economic status (SES), are indicators of unequal access to and use of ICT (NTIA 2000; NTIA 2002) . Until recently, however, another form of stratification has been largely overlooked both in broad terms and in terms of digital inequality specifically: a possible “disability divide" (Solomon 2000).

In the past five years, research on inequality in access to and use of new media has turned its attention to the experience of people with disabilities. Though this research has shed light on the benefits and barriers new media provide for people with disabilities, several issues with these studies have prevented a clear answer of some important questions. Though they have led to great insights, many existing studies draw from small and/or nonrepresentative samples (e.g., Bradley and Poppen 2003; Finn 1999; Grimaldi and Goette 1999; Guo, Bricout and Huang 2005; Seymour and Lupton 2004).

The studies that have used large, random samples (Kaye 2000; Lenhart et al. 2003; Mann et al. 2005; NTIA 2000; NTIA 2002) have limited their analysis to descriptive statistics. Finally, there has been little consistency between studies in the definition of disability. No doubt this is due to the fact that the definition of what constitutes disability is debated (World Wide Web Consortium 2004). Taken together, these issues have hampered attempts to discern causal relationships concerning digital inequality concerning disability status. 
Through quantitative analyses of a nationally representative sample of Americans with and without disabilities drawn in 2003, this article addresses the relationship between disability status and access to and use of the Internet. We start by discussing the benefits of and barriers to ICT by people with disabilities and then review what existing work has found about this area of inquiry. Based on research by others and related work on digital inequality, we formulate hypotheses for our study. Next, we present the data set and our methodology followed by a discussion of our findings and their implications for research on both the disability divide and digital inequality more broadly speaking.

\section{THE BENEFITS AND BARRIERS OF INTERNET USE BY PEOPLE WITH DISABILITIES}

Existing literature on the Internet and people with disabilities offers both positive and negative perspectives, often within the same study. While Internet use offers a wealth of information and interaction that those with disabilities would otherwise have a difficult time accessing and thus can lead to improvements in both physical- and mental-health outcomes, these benefits are not available to many people with disabilities, and may in fact reinforce the unequal status of people with disabilities in society (Goggin and Newell 2003). This is because of barriers to both access to and effective use of the Internet by those with disabilities. In this section we review current literature on the promise of and hurdles to Internet access and use for individuals with disabilities.

\section{Benefits}

For years commentators and researchers have hailed the Internet and other new media as tools with which previously disadvantaged or oppressed groups could overcome impediments or domination (Anderson et al. 1995; Rushkoff 1996; Schwartz 1996). Although more recently some have disputed or qualified such claims (Margolis and Resnick 
2000; Norris 2001; Sunstein 2001), such an empowering perspective has persisted. ICT have been seen in a similarly positive light by some researchers in disability studies. Much the way that medical and other forms of assistive technology have improved the physical functioning of people with disabilities, ICT have been viewed as tools that enable people with disabilities to escape the isolation and stigma that sometimes accompany their disabilities. Internet access has been shown to improve how individuals with disabilities evaluate their level and quality of communication with others (Bradley and Poppen 2003) and their sense of independence and self-determination (Cook et al. 2005; Grimaldi and Goette 1999).

The benefits of ICT use are not limited to the psychological realm. Use of ICT has been shown to improve health outcomes, such as reduced length and frequency of hospital stays, for elderly individuals with disabilities (Magnusson, Hanson and Borg 2004) and an improvement of "health-related quality of life" for people with spinal cord injuries (Drainoni et al. 2004). This range of benefits is seen to come about because people with disabilities are able to obtain more and better information. A survey completed by the National Center for the Dissemination of Disability Research found that the disabled are finding information regarding disability online more and more (NCDDR 2000). People with disabilities can also use the Internet's expansive communication capabilities to strengthen existing relationships with family and friends and to establish new meaningful relationships.

Online communication resources for people with disabilities are extensive. Numerous self-help groups have arisen on the Internet that mimic many of the social support and therapeutic processes of offline self-help and social work groups (Finn 1999). However, unlike traditional support groups that rely heavily on physical co-presence, people can take advantage of online support without leaving their homes. People with disabilities can find many chat rooms and mailing lists that cater specifically to individuals with 
disabilities. Thousands of such communities exist, focusing on topics ranging from serious medical discussions to socializing about recreational activities. ${ }^{1}$ One study found that such sites were the preferred online location of people with disabilities (Seymour and Lupton 2004).

The most striking aspect of online communication for people with disabilities is the ability it affords the user to hide aspects of him- or herself. For people with disabilities, online communication may allow the removal of their disability from the forefront of interaction until it is relevant or desirable to reveal (Bowker and Tuffin 2002).. Unlike communication in the offline world, where the stigma of disability (Goffman 1963) or one's impairment itself may at times prevent one from venturing into the world freely and interacting with others, online communication allows the individual with disability to encounter and interact with others to a degree that may not be possible offline.(Guo, Bricout and Huang 2005; Seymour and Lupton 2004). However, not all individuals with disabilities go online, and there are substantial barriers preventing them from doing so. It is to these barriers that we now turn.

\section{Barriers}

Depending on the type of disability an individual has, as well as the availability of assistive technology, ICT may be more or less accessible. Moreover, there are different types of accessibility: even if people with disabilities have physical Internet access, the hardware or software providing the Internet access may not be configured to allow those with disabilities to use it (World Wide Web Consortium 2004). Many individuals with disabilities require assistive technology to use computers and the Internet (Mann et al. 2005; World Wide Web

\footnotetext{
${ }^{1}$ A simple search on two popular discussion group aggregator sites (Yahoo! Groups and Google Groups) yields well over a thousand mailing lists devoted to such topics.
} 
Consortium 2004). For example, blind individuals use screen reading programs such as JAWS and/or refreshable Braille displays to read what is on the screen. Even with such accommodations, much of the Web is still not accessible to people with disabilities, forcing organizations for these individuals to come up with their own accommodations (D'Amour 2004). If these efforts are unsuccessful, individuals with disabilities simply cannot access certain resources online, such as Web sites that do not meet particular requirements.

Complicating things further, much assistive technology is reactive in design, and by the time accommodations are made, technology has often moved another step forward. This results in the need for new accommodations and the potential for a constant lagging behind by disabled users. Many in the disability rights and research community push for a proactive approach in which technology is created to be accessible by all in the first place (Stephandis and Emiliani 1999).

Though it appears that over time, conditions have improved for people with disabilities online, barriers still exist. A 1998 report by the National Council on Disability proclaimed "the current state of multimedia access for people with sensory disabilities is bleak" (National Council on Disabilities 1998:3). By contrast, the December, 2004 version of the World Wide Web Consortium's working paper How People with Disabilities Use the Web (World Wide Web Consortium 2004), though acknowledging barriers, also acknowledges that many barriers can be overcome through adaptive technology. For example, the paper describes a hypothetical accountant with blindness who is able to do her job because her screen reader is able to interpret the accessibly-designed forms, browser and intranet pages of her company. In another hypothetical case, a retiree with several age-related conditions is able to do his personal finances thanks to certain Web pages with style sheets, which allow him to alter text formatting. Thus, advancements in technology have been made to 
accommodate the special needs of people with disabilities; however, these users still have many hurdles to efficient access that other users do not encounter.

Another barrier to use is cost. Adaptive technology that renders otherwise inaccessible technology usable by people with disabilities is sometimes expensive. For example, as Lenhart et al. (2003) point out, Braille interface machines can run $\$ 3000$ and magnified screens can cost $\$ 2000$. Combine this with the fact that people with disabilities generally have less income than those without, and we confront a major obstacle for people with disabilities using ICT (Lenhart et al. 2003).

It may be that some people simply do not want to go online. While at times the result of an informed choice, in other instances such a decision may reflect a lack of understanding about the opportunities offered by the system. Some people may not express interest in Internet use, because they do not realize the wealth of information and social connections use of the medium would make possible. Mere connectivity does not equal efficient and informed use. People may try the medium and opt out of its use after disappointments either due to lack of easily accessible relevant content or usability concerns. Some people may never develop an interest if they hear nothing but frustrating experiences from those in their social circles.

Thanks to changes in government policy, however, we do see improvement in ICT accessibility by people with disabilities. In the United States, the 1998 amendment to Section 508 of the Workforce Rehabilitation Act, which was passed by Congress and signed by President Clinton, mandates that Federal agencies must use ICT that is accessible to workers and members of the public who are disabled. The Americans with Disabilities Act could potentially be used to file suit against companies with inaccessible Web sites, though 
the first US Federal court opinion on the topic has ruled against its application (National Council on Disability 2003).

\section{EXISTING EMPIRICAL INVESTIGATIONS}

Numerous studies in the United States have found that people with disabilities lag behind those without disabilities in access to computers and the Internet (Kaye 2000; NTIA 2000; NTIA 2002). Lack of consistency in defining exactly what constitutes a disability makes comparison across studies difficult, but the findings suggest that this inequality is persistent and prevalent. For example, with a few exceptions, even within demographic subgroups (racial/ethnic, age, gender), those with disabilities lag behind those without. ${ }^{2}$ The reports suggest that disparities shrink with rising income. Though the statistics contained in the reports are compelling, they are only descriptive in nature. Consequently, they cannot tell us much about the independent effect of the various factors that may explain why users with disabilities lag behind those without disabilities in Internet access and use.

The technical barriers preventing people with disabilities are rather clear. The ways in which disability overlaps with other social categories in society has clouded the understanding of the relative causal significance of many social factors in the ICT uses of people with disabilities. Individuals with disabilities tend to be older and poorer than the general population, and are more likely to be unemployed (Kaye 2000; Lenhart et al. 2003; NTIA 2000). Due to these factors, the relative impact of disability itself is difficult to determine with the descriptive statistics that have been the predominant type of analysis performed thus far on this topic.

\footnotetext{
2 Among Latinos, the differences in Internet access rates are not significantly different between those with and without disabilities (Kaye 2000).
} 
Disability is a significant but often-overlooked social status in society with dynamics and social consequences similar to other social statuses such as race (Gordon and Rosenblum 2001). Because of this, it is important to understand the forces driving inequality, including inequality in access to ICT. Moreover, we need to understand how other statuses interact with disability with respect to ICT access. However, research should not end with understanding differences in access to ICT (DiMaggio et al. 2004a). Rather, it is also important to look at differences in what people do online once they have gained access.

The limited research that exists in this realm suggests that people with disabilities tend to focus their time online toward disability-related activities (Seymour and Lupton 2004). As discussed above, online chat rooms, mailing lists and support groups exist for people with disabilities. In addition, people with disabilities are more likely to look for health-related information online (NTIA 2002). Individuals with disabilities are also more likely to play games on the Internet (NTIA 2002). Much more research is needed in this domain, however.

\section{RESEARCH QUESTIONS}

Based on the gaps in the existing literature, our main research questions are as follows.

1. How does computer ownership and Internet access of people with disabilities compare to computer ownership and Internet access by people without disabilities?

2. Among those who are online, how do the Internet uses of people with disabilities compare to the Internet uses of people without disabilities?

3. How do computer ownership, Internet access and Internet use differ by type of disability? 


\section{DATA AND METHODS}

We use data from the Computer and Internet Use Supplement (CUIS) of the Current Population Survey (CPS) administered in October, 2003 by the U.S. Bureau of Labor Statistics and the Bureau of the Census (NTIA 2002). This data set is particularly well-suited to answer the questions of interest presented in this paper. First, the data set is administered on a large number of respondents randomly sampled from the American population. Second, the survey collected detailed information about people's computer and Internet uses. Third, the survey asked respondents to identify whether they have any one of five long-lasting physical disabilities. Thanks to the size of the sample there are thousands of people with disabilities included in the data set allowing for advanced quantitative analyses.

With respect to people's disability status, the CPS CIUS includes information about the following questions: ${ }^{3}$

- Do you have the following long-lasting physical condition?

A. Blindness or a severe vision impairment even with glasses or contact lenses?

B. Deafness or a severe hearing impairment even with a hearing aid?

C. A physical condition that substantially limits your ability to walk or climb stairs?

D. A condition that makes it difficult to type on an ordinary typewriter or traditional computer keyboard?

- Do you have difficulty going outside the home alone, for example, to shop or visit a doctor's office, because of a physical or mental health condition lasting 6 months or longer?

\footnotetext{
${ }^{3}$ Ideally we would have even more refined data, but this is the extent to which the topic is covered in the data set. For example, there are no questions about the availability and use of assistive technologies.
} 
The CPS collects data on all members of a household by asking one member to report for all other household residents. Because we believe that proxy reports about people's online activities are unlikely to be reliable (e.g., it is questionable whether a spouse, child or parent will be able to say reliably in what types of online activities a household member engages), we only look at self-reports in the data set. We restrict our analyses to adults 18 years and over.

There are 54,956 respondents in our data set. Table 1 presents descriptive statistics about the sample. Since women are more likely to respond to surveys (e.g. Rizzo, Brick and Park 2004; Smith 1979) and we restricted our analyses to self-reports, female respondents are overrepresented, constituting 61 percent of the sample. African Americans represent ten percent of the sample and nine percent of participants indicated Hispanic origin. The education level of respondents is representative of national figures, given that the majority has less than a college degree. Sixty-one percent of respondents are employed full or part time.

\section{INSERT TABLE 1 ABOUT HERE}

As mentioned earlier, the October 2003 Computer and Internet Use Supplement of the Current Population Survey offers a unique opportunity to examine the relationship between disability status and Internet use due to the large number of people with disabilities who were included in the study. Table 2 describes the number of such people in the sample. Thirteen percent of all respondents or 6,584 people indicated at least one type of physical limitation. The most common disability is difficulty with walking; nine percent of the whole sample described themselves as having this impairment. Five percent of the sample have such severe disabilities that they are unable to leave the home, while three percent have 
difficulty typing two percent have hearing, and two percent have a sight impairments. Fortyfour percent of the sample report having more than one disability.

INSERT TABLE 2 ABOUT HERE

In our analyses below, we pay particular attention to computer and Internet access and use in the home. The home is the most autonomous of all access locations providing around-the-clock access. While Internet use at work or at libraries and community centers offers viable alternatives, these locations come with considerable constraints either due to limitations posed on usage by employers or the monitoring activities of staff members. Thus we feel it important to pay particular attention to disparities in home access and use.

We start by presenting data about the presence of a computer in the household and whether the respondent uses a computer at home. Next, we look at the availability of Internet connection in the household and whether the respondent goes online at home. We list the relevant statistics for the entire sample and then for people without disabilities and people with disabilities, respectively. We also disaggregate the data by type of disability and include figures for those with multiple disabilities.

In the subsequent section we turn to more nuanced analyses of what predicts Internet use anywhere. We use logistic regression to predict likelihood of Internet use when controlling for several demographic characteristics such as age, gender, race, ethnicity, education, and income, type of metropolitan status, region of the country, employment status and whether the respondent lives alone. Age and income are included in the analyses as continuous variables while all others are included as dummy variables. ${ }^{4}$ For education,

\footnotetext{
${ }^{4}$ We performed a log transformation on the income variable, because it makes sense to assume that the payoff of additional dollars diminishes as one moves up the scale. Moreover, this was important to meet the normal distribution requirement for logistic regression analysis.
} 
having a college degree is the baseline category; for metropolitan status, it is living in an urban location. The Northeast region serves as the baseline for area of the country.

Finally, we look at descriptive statistics regarding the types of online activities in which people engage, broken down by disability status. We present percentages of respondents in both groups who engage in the listed activities and also note whether these differences are statistically significant.

\section{INTERNET ACCESS AND USE AT HOME}

Tables 3-6 present bivariate statistics, respectively, about whether the respondent (1) lives in a household with a computer (Table 3); (2) uses a computer at home (Table 4); (3) has Internet access in the household (Table 5); and (4) goes online at home (Table 6). In each case, we also present data taking into consideration the availability or use of the technology upon which the respective access or use is contingent. More precisely, in Table 4 , in addition to listing the percentage of all respondents who use a computer at home, we also look at - in the right column of the table - what these figures look like among those who have a computer in the household. That is, we control for the necessary precondition of the activity in question.

According to the figures in Table 3 describing computer presence in households, people with disabilities are much less likely to have such a device in the home than those without disabilities. The figure is below 40 percent for those with disabilities, in stark contrast to 63.6 percent for others. The least equipped households are those with people who have such serious disabilities that they have difficulties leaving the home. Only 31 percent of this subset lives in households with computers.

TABLE 3 ABOUT HERE 
The statistics presented in Table 4 suggest that while over half of people without disabilities use a computer at home, less than a third of those with disabilities do so. Among those with considerable limitations in leaving the home - the category that likely represents those with some of the most severe impairments - only slightly more than a fifth uses a computer at home. When controlling for the availability of computers in the home (the figures on the right side of Table 4) people with disabilities are still considerably less likely to be computer users at 76.1 percent with a difference of about ten percentage points as compared to those without disabilities (87.1 percent).

\section{TABLE 4 ABOUT HERE}

The next two tables look at Internet access and use in the home. Figures in Table 5 indicate the disparities between people with and without disabilities with respect to residing in a household that has Internet access. Similarly to earlier figures, the differences regarding disability status are considerable. In Table 6 we see the level of use at home. While over half of people without impairments access the network in their homes, just over a quarter of those with disabilities do so, highlighting considerable disparities. We see here that there is a close relationship between using a computer and going online at home regardless of disability status, as the figures in the third column are in the upper nineties for both groups. However, simply living in a household with Internet access is much less likely to be associated with use as suggested by the numbers in the last column.

\section{TABLES 5 AND 6 ABOUT HERE}

Table 7 presents figures for Internet access anywhere. Almost two-thirds of people without disabilities (63.6 percent) go online at some location, whereas less than one third (30.8 percent) of those with reported impairments do so. Given that several of the disability conditions accounted for in the survey concern difficulty in physical movement, it is not 
surprising that expanding our analysis to include locations outside of the home does not raise the connectivity levels of people with disabilities to high levels. In particular - and not surprisingly - those who indicated difficulty with walking or leaving the home are, along with those with multiple disabilities, the least likely to see a large jump in level of use between home use only and use anywhere.

TABLE 7 ABOUT HERE

\section{EXPLAINING DIFFERENCES IN INTERNET USE}

Next we turn to a more nuanced look at what explains Internet use. In particular, we examine whether various socio-economic factors associated with disability status (e.g., lower income, lower likelihood of full- or part-time employment and others) explain the disparities in level of computer and Internet uses between those with and without disabilities. Table 8 presents the results of logistic regression analyses looking at the likelihood that a respondent is an Internet user controlling for various demographic characteristics.

\section{TABLE 8 ABOUT HERE}

In the first model we do not include disability status so we can ascertain the relationship of the variables with Internet use independent of our main focus. Other than region of the country (i.e., being in the Midwest shows no difference as compared to residing in the Northeast) all of the variables in the model are significant. We find that older people, African Americans and Hispanics are less likely to be users, as are those with lower levels of education and income. Women are more likely to be online as are those who are employed full- or part-time. Those living in rural locations have lower rates of connectivity than those residing in urban areas, but suburban residents exhibit the highest levels of use. Living alone shows a negative relationship to going online. 
In Model 2 we include information about people's disability status. We add one variable indicating whether the respondent has any type of impairment included in the survey. Findings suggest that there is an independent effect of having a disability on the likelihood of being an Internet user. When controlling for characteristics such as education, income and employment status, people with disabilities are still less likely to be making Internet use a part of their lives. Even among those with higher socio-economic status, having a disability constitutes a barrier to using the Internet. ${ }^{5}$

In Model 3 we take a more nuanced look at people's disability status. Instead of including one measure for any type of disability, we include information on each type of physical impairment identified by respondents. We find that not all conditions have an independent effect on Internet use. After controlling for people's socio-economic background and other demographic characteristics, neither hearing impairment nor limited walking ability is a statistically significant predictor of Internet use.

This is an important discovery, as it suggests that - when controlling for other factors - in cases where the particular disability has little to do with using a computer there are few significant barriers to use. In contrast, disabilities that are more directly tied to using a computer - visual impairment, difficulty typing - continue to exhibit independent effects on use. These results imply that technological barriers are the likely culprit preventing people with certain disabilities from going online.

\section{TYPES OF INTERNET USES}

\footnotetext{
${ }^{5}$ In another model (not reported) with the same control variables, we included a variable for the number of disabilities the respondent reports (logged so as to give less weight to each additional disability). The variable was significant at the $\mathrm{p}<.000$, indicating that the more disabilities an individual has, the more likely he or she is to face barriers to Internet access and use.
} 
In Table 9 we take a more detailed look at what types of Web sites and online services people utilize. We present what percentage of respondents engage in various online activities, disaggregated by disability status. The third column indicates whether the level of engagement is statistically significant between the two groups.

\section{TABLE 9 ABOUT HERE}

In almost all cases people without disabilities are more likely to frequent a type of Web site or look for a particular type of service and these differences are statistically significant. Those without impairments are more likely to communicate with others (use of email or instant messaging), they are more likely to search for product information or make purchases, to get news, bank online, trade stocks, take courses or search for jobs on the Web. These are all activities that can be beneficial to the user by saving time and providing new opportunities through up-to-date information and materials that may not be similarly accessible otherwise. The fact that people with disabilities are less likely to engage in them is a concern. It suggests that even among those who are online such "capital-enhancing" uses of the Web are less likely and so the payoffs of Internet use will be weaker.

There are a few activities in which people with impairments are more likely to engage online than their non-disabled counterparts. They are more likely to look for health information, play games and search for information about government services. Given the particular relevance of health-related content to this segment of the population, these findings are understandable. Playing games online may be a way to pass time or to connect to others, assuming these are multi-player games across the network, a detail not available on the survey.

It is understandable that people with disabilities would want to learn about government services and agencies and may do so at higher levels than the average user. 
However, it is important to note that while looking for such information is more common among people with impairments, these people are no more likely than others to download federal, state or local government forms and are less likely at a statistically significant level to submit completed forms than those without disabilities. This discrepancy may well be due to the fact that downloading such forms and filling them out requires better resources (e.g. additional software, high speed connectivity) and a more advanced know-how of Web use both of which may be less widespread among those with disabilities.

\section{DISCUSSION AND CONCLUSION}

This study has demonstrated that there is, indeed, a disability divide that needs to be taken into consideration when discussing digital inequality. Whether it is in terms of access to or use of computers and the Internet, many people with disabilities lag behind those without such impairments. However, the relationship of disability status with ICT uses is not universal regardless of type of impairment highlighting the importance of more nuanced measures and a focus on the specifics of people's conditions.

Those who indicated difficulty with leaving the home may have more severe disabilities that globally reduce their functioning (e.g., spinal cord injuries and other types of paralysis, multiple sclerosis), leading them to require more advanced and more expensive assistive technologies, raising additional costs and accessibility barriers to use. Moreover, it is also possible that the existing and most easily available assistive technologies do not work as well for people with disabilities. Given that disability status is often associated with lower levels of income and employment, it is not surprising that the overall descriptive statistics presented in Tables 3-6 show considerably lower levels of use among those with impairments. 
For many people with disabilities such as those with significant trouble leaving their homes and the blind, while demographic and socio-economic factors play a role in lower levels of access to and use of computers and the Internet, these do not explain the discrepancies in connectivity levels on their own. We argue that technical accessibility barriers are likely the cause of these groups' lagging behind those without disabilities. Not only is adaptive technology difficult to learn and expensive, but it lags in development behind the technology to which it is supposed to enable access.

However, as we have shown, not all people with disabilities are equally disadvantaged. We see that other social statuses that affect likelihood of access to and use of ICT, such as income, education and labor-force participation can explain some of the inequality between those with and without disabilities. Since these characteristics often go hand-in-hand with one's disability status it is especially important to analyze data in a way that controls for other social factors.

We also found considerable differences in how those online make use of their connectivity; users with disabilities were less likely to browse several types of Web sites from which they may benefit. Far from reflecting individual preferences per se, these online actions may also mirror technical barriers and discrepancies in Internet-use know-how. Depending on the quality of connections, hardware and software capabilities, those with fewer means will have a harder time accessing a diverse set of Web sites. Moreover, as multi-media content becomes more widespread such limitations will pose even greater barriers to online material. This may have implications even for those whose level of connectivity is not lower than that of people with disabilities, namely, the hearing impaired. As multi-media files proliferate, deafness may become more of a barrier than it is today. 
These findings suggest the need for public policy that encourages access to assistive technologies that are more affordable and more up-to-date to help bridge the divide between people with and without disabilities. In addition to such measures, policy supporting the development of technology that is universally accessible from inception would help avoid lags between when new technology is developed and when assistive technology making it accessible becomes available.

In addition to technical barriers, lack of sufficient knowledge about the medium may hinder uses as well. Users are less likely to seek certain types of material if they are not aware either that particular types of content exist online or how they may be able to access different materials. Moreover, given that numerous Web sites are not made available in accessible formats, they serve limited use to those who have difficulty seeing them or navigating complicated layouts that may require very exact motor skills. Given that users can learn much from freely browsing the Web, by not being able to browse as freely as others, Internet users with disabilities will have fewer opportunities to learn about online services.

Much research remains to be done in the realm of ICT use by people with disabilities. More research is needed on understanding why people with disabilities access fewer types of content than individuals without disabilities. It may be that not enough relevant content is available or is easily accessible for this segment of the population.

Although the Computer and Internet Use Supplement of the Current Population Survey allows heretofore impossible analyses on access and use questions for people with disabilities, there are several issues it does not address that we would have liked to have included in this study and whose exploration will be important in the future. First, the CPS does not ask respondents whether anyone in their household has and/or uses adaptive 
technology to access a computer or the Internet. Such a question would allow a deeper understanding of the role of technical accessibility issues in the disability divide.

Second, the number of disabilities listed on the CPS limits the extent to which the situation of people with different impairments can be compared. A more in-depth understanding of relevant issues would require more nuanced categorization of disability status. Psychiatric and mental disabilities are only included in this survey to the extent that they make it difficult to leave the house. Without more information on psychiatric and mental impairments it is hard to know how such conditions influence computer and Internet uses. Learning disabilities are also omitted from the CPS.

Analyses of large representative data sets are helpful for providing generalizable findings in response to research questions. Such information can be useful for framing and focusing more in-depth studies of the phenomena under investigation. In this paper we provide context for more refined studies of ICT uses by people with disabilities. Results suggest that numerous factors pose barriers to ICT access for those with disabilities. Moreover, we find that it is misleading to collapse different types of disabilities into one category, as likelihood of Internet use is not always related to disability status. Future data collection efforts should try to disaggregate categories and studies should be mindful of the divergent situations faced by people living with different disabilities. 
TABle 1. SAMPle Descriptives ${ }^{6}$

\begin{tabular}{|c|c|c|c|}
\hline Age & 48.5 & 16.8 & 54,956 \\
\hline Gender (female $=1$, male $=0$ ) & .61 & .49 & 54,956 \\
\hline African American (=1) & .10 & .30 & 54,956 \\
\hline Hispanic (=1) & .09 & .28 & 54,956 \\
\hline Did not graduate from high school & .13 & .34 & 54,956 \\
\hline High school, no college & .32 & .47 & 54,956 \\
\hline Some college, no degree & .28 & .45 & 54,956 \\
\hline College degree & .18 & .38 & 54,956 \\
\hline Graduate degree & .09 & .29 & 54,956 \\
\hline Household income & 53,442 & 48,027 & 46,059 \\
\hline Urban location & .27 & .44 & 46,025 \\
\hline Suburban location & .43 & .50 & 46,025 \\
\hline Rural location & .30 & .46 & 46,025 \\
\hline Northeast region & .22 & .41 & 54,956 \\
\hline Midwest region & .25 & .43 & 54,956 \\
\hline South region & .29 & .46 & 54,956 \\
\hline West region & .24 & .43 & 54,956 \\
\hline Employed full- or part-time & .61 & .49 & 54,956 \\
\hline Lives alone & .40 & .49 & 54,956 \\
\hline
\end{tabular}

\footnotetext{
${ }^{6}$ Unless otherwise indicated in parentheses after the name of the variable, values are 0-1 where the variable gets 1 if the variable's title is in the affirmative (e.g. "High school, no degree" $1=$ yes; $0=$ no).
} 


\begin{tabular}{lcccc} 
TABLE 2. Proportion OF PEOPle WITH Disabilities IN THE SAMPLE \\
& \multicolumn{4}{c}{$\begin{array}{c}\text { Current Population } \\
\text { Survey 2003 }\end{array}$} \\
& Mean & St.Dev. & Frequency & N \\
\cline { 2 - 5 } Any disability & .13 & .34 & 6,584 & 50,129 \\
Disability: blind/sight difficulty & .02 & .15 & 1,099 & 50,165 \\
Disability: deaf/hearing difficulty & .02 & .14 & 1,068 & 50,165 \\
Disability: limited walking ability & .09 & .29 & 4,707 & 50,165 \\
Disability: difficulty typing & .03 & .17 & 1,443 & 50,165 \\
Disability: difficulty leaving home & .05 & .22 & 2,479 & 50,190 \\
Multiple disabilities & .06 & .23 & 2,907 & 50,129
\end{tabular}

Table 3. Percentage of People Living in Households with Computers

\begin{tabular}{lcc}
\cline { 2 - 3 } All respondents & 63.1 & 54,956 \\
No disability & 63.6 & 43,545 \\
Disability & 39.7 & 6,584 \\
By type of disability & & \\
Blindness/sight difficulty & 36.9 & 1,099 \\
Deafness/hearing difficulty & 38.6 & 1,068 \\
Limited walking ability & 37.5 & 4,707 \\
Difficulty typing & 39.6 & 1,443 \\
Difficulty leaving home & 31.7 & 2,479 \\
Multiple disabilities & 32.1 & 2,907
\end{tabular}


Table 4. Percentage of People Who Use a Computer at Home

\begin{tabular}{lcccc} 
& \multicolumn{2}{c}{$\begin{array}{c}\text { Among all } \\
\text { respondents }\end{array}$} & \multicolumn{2}{c}{$\begin{array}{c}\text { Among those who } \\
\text { have a computer in } \\
\text { the household }\end{array}$} \\
\cline { 2 - 5 } Percent & $\mathrm{N}$ & Percent & $\mathrm{N}$ \\
\cline { 2 - 5 } All respondents & 54.3 & 54,956 & 86.1 & 34,669 \\
No disability & 57.6 & 43,545 & 87.1 & 28,790 \\
Disability & 30.2 & 6,584 & 76.1 & 2,616 \\
By type of disability & & & & \\
Blindness/sight difficulty & 26.2 & 1,099 & 70.9 & 406 \\
Deafness/hearing difficulty & 29.5 & 1,068 & 76.5 & 412 \\
Limited walking ability & 28.0 & 4,707 & 74.5 & 1,767 \\
Difficulty typing & 30.0 & 1,443 & 75.8 & 571 \\
Difficulty leaving home & 22.2 & 2,479 & 70.0 & 787 \\
Multiple disabilities & 22.4 & 2,907 & 69.5 & 935
\end{tabular}

Table 5. Percentage of People living in Households With Internet ACCESS

\begin{tabular}{|c|c|c|c|c|c|c|}
\hline & \multicolumn{2}{|c|}{$\begin{array}{l}\text { Among all } \\
\text { respondents }\end{array}$} & \multicolumn{2}{|c|}{$\begin{array}{l}\text { Among those who } \\
\text { have a computer in } \\
\text { the household }\end{array}$} & \multicolumn{2}{|c|}{$\begin{array}{c}\text { Among those who } \\
\text { use a computer at } \\
\text { home }\end{array}$} \\
\hline & Percent & $\mathrm{n}$ & Percent & $\mathrm{n}$ & Percent & $\mathrm{n}$ \\
\hline All respondents & 55.9 & 54,956 & 87.9 & 34,669 & 91.9 & 29,848 \\
\hline No disability & 59.1 & 43,545 & 88.6 & 28,790 & 92.3 & 25,078 \\
\hline Disability & 33.0 & 6,584 & 81.8 & 2,616 & 87.3 & 1,991 \\
\hline \multicolumn{7}{|l|}{ By type of disability } \\
\hline $\begin{array}{l}\text { Blindness/sight } \\
\text { difficulty }\end{array}$ & 31.3 & 1,099 & 82.5 & 406 & 88.5 & 288 \\
\hline $\begin{array}{l}\text { Deafness/hearing } \\
\text { difficulty }\end{array}$ & 33.2 & 1,068 & 84.7 & 412 & 88.2 & 315 \\
\hline $\begin{array}{l}\text { Limited walking } \\
\text { ability }\end{array}$ & 30.7 & 4,707 & 80.7 & 1,767 & 86.7 & 1,317 \\
\hline Difficulty typing & 32.2 & 1,443 & 80.4 & 571 & 86.1 & 433 \\
\hline $\begin{array}{l}\text { Difficulty leaving } \\
\text { home }\end{array}$ & 26.4 & 2,479 & 82.1 & 787 & 87.5 & 551 \\
\hline Multiple disabilities & 26.3 & 2,709 & 80.4 & 935 & 87.1 & 650 \\
\hline
\end{tabular}


Table 6. Percentage of People Who Use the Internet at Home

\begin{tabular}{|c|c|c|c|c|c|c|c|c|}
\hline & \multicolumn{2}{|c|}{$\begin{array}{l}\text { Among all } \\
\text { respondents }\end{array}$} & \multicolumn{2}{|c|}{$\begin{array}{l}\text { Among those } \\
\text { who have a } \\
\text { computer in the } \\
\text { household }\end{array}$} & \multicolumn{2}{|c|}{$\begin{array}{l}\text { Among those } \\
\text { who use a } \\
\text { computer at } \\
\text { home }\end{array}$} & \multicolumn{2}{|c|}{$\begin{array}{l}\text { Among those } \\
\text { who have } \\
\text { Internet } \\
\text { access at } \\
\text { home }\end{array}$} \\
\hline & $\%$ & $N$ & $\%$ & $\mathrm{~N}$ & $\%$ & $\mathrm{~N}$ & $\%$ & $\mathrm{~N}$ \\
\hline All respondents & 50.8 & 52,462 & 82.9 & 32,175 & 97.5 & 27,354 & 86.9 & 30,683 \\
\hline No disability & 54.4 & 41,665 & 84.2 & 26,910 & 97.7 & 23,198 & 88.2 & 25,673 \\
\hline Disability & 26.4 & 6,328 & 70.9 & 2,360 & 96.4 & 1,735 & 77.1 & 2,169 \\
\hline \multicolumn{9}{|l|}{ By type of disability } \\
\hline $\begin{array}{l}\text { Blindness/sight } \\
\text { difficulty }\end{array}$ & 23.2 & 1,066 & 66.2 & 373 & 96.9 & 255 & 71.8 & 344 \\
\hline $\begin{array}{l}\text { Deafness/hearing } \\
\text { difficulty }\end{array}$ & 25.9 & 1,030 & 71.4 & 374 & 96.4 & 277 & 75.6 & 353 \\
\hline Limited walking ability & 24.2 & 4,530 & 68.9 & 1,590 & 96.1 & 1,140 & 75.8 & 1,444 \\
\hline Difficulty typing & 26.1 & 1,382 & 70.6 & 510 & 96.8 & 372 & 77.8 & 463 \\
\hline $\begin{array}{l}\text { Difficulty leaving } \\
\text { home }\end{array}$ & 19.3 & 2,408 & 64.9 & 716 & 96.9 & 480 & 71.2 & 653 \\
\hline Multiple disabilities & 19.2 & 2,821 & 63.8 & 849 & 96.1 & 564 & 71.2 & 761 \\
\hline
\end{tabular}

Table 7. Percentage of People Who Use the Internet Anywhere

$\begin{array}{lcc} & \text { Percent } & \mathrm{N} \\ \text { All respondents } & 59.7 & 54,956 \\ \text { No disability } & 63.6 & 43,545 \\ \text { Disability } & 30.8 & 6,584 \\ \text { By type of disability } & & \\ \text { Blindness/sight difficulty } & 29.2 & 1,099 \\ \text { Deafness/hearing difficulty } & 30.8 & 1,068 \\ \text { Limited walking ability } & 27.6 & 4,707 \\ \text { Difficulty typing } & 30.2 & 1,443 \\ \text { Difficulty leaving home } & 22.4 & 2,479 \\ \text { Multiple disabilities } & 22.5 & 2,709\end{array}$


Table 8. Logistic Regression Predicting Internet Use AnYwhere*

Age

Gender (female=1, male $=0$ )

African American

Hispanic

Did not graduate from high school

High school, no college

Some college, no degree

Graduate degree

Household income (logged)

Rural location

Suburban location

Midwest region

South region

West region

Employed full- or part-time

Lives alone

Has disability

Blindness/sight difficulty

Deafness/hearing difficulty

Limited walking ability

Difficulty typing

Difficulty leaving home

$-0$

Model 1

Model 2

$-0.04(.00)$

-0.05 (.00)

Model 3

$0.28(.03)$

0.29 (.03)

$-0.05(.00)$

$-0.61(.03)$

$-0.61(.05)$

$0.29(.03)$

-1.05 (.05)

-1.03 (.05)

$-0.61(.05)$

$-2.67(.06)$

$-2.77(.06)$

-1.03 (.05)

-1.69 (.05)

$-1.72(.05)$

$-2.77(.06)$

$-0.72(.05)$

$-0.68(.05)$

$-1.72(.05)$

$0.44(.07)$

0.49 (.08)

$-0.68(.05)$

$0.63(.02)$

$0.64(.02)$

$0.49(.08)$

-0.08 (0.04)

-0.07 (0.04)

$0.64(.02)$

$0.11(0.04)$

$0.12(0.04)$

-0.07 (0.04)

$-0.03(0.04)$

-0.02 (0.04)

$0.11(0.04)$

-0.07 (0.04)

-0.08 (0.04)

$-0.02(0.4)$

$0.14(0.04)$

0.13 (0.04)

-0.08 (0.04)

$0.49(.04)$

$0.44(.03)$

0.13 (0.04)

$-0.17(.03)$

$-0.16(.03)$

$0.43(.03)$

$-0.16(.03)$

$-0.19(.04)$

$\begin{array}{ccc} & -0.01(0.10) \\ & -0.05(0.11) \\ & -0.19(0.06) \\ & -0.27(0.09) \\ -3.08(.20) & -3.10(.21) & -0.01(.21) \\ 38,386 & 35,920 & 35,907 \\ 0.3328 & 0.3432 & 0.3436\end{array}$

Pseudo $\mathbf{R}^{2}$

0.3328

0.3432

* The reported figures are the logit coefficients. The numbers in parentheses are standard errors. All coefficients are significant at the $<.05$ level except the ones indicated in italics. Most are significant at the $\mathrm{p}<.000$ level. 
Table 9. Percentage of People Who Engage in Various Online ACTIVITIES*

\begin{tabular}{lccc} 
& $\begin{array}{c}\text { People } \\
\text { without } \\
\text { Disabilities }\end{array}$ & $\begin{array}{c}\text { People } \\
\text { with } \\
\text { Disabilities }\end{array}$ & $\begin{array}{c}\text { Significant } \\
\text { Difference } \\
\text { (P value) }\end{array}$ \\
Email or instant messaging & 88.9 & 83.5 & 0.000 \\
Searching for product information & 80.7 & 76.1 & 0.000 \\
Getting news, weather or sports information & 69.5 & 65.6 & 0.000 \\
Purchasing products or services & 58.0 & 50.5 & 0.000 \\
Looking for health information & 48.3 & 57.3 & 0.000 \\
Searching for information about government services & 42.3 & 46.8 & 0.000 \\
\hline Downloading government forms & 32.3 & 32.4 & 0.963 \\
Submitting completed government forms & 21.5 & 19.6 & 0.046 \\
Playing games & 33.6 & 37.8 & 0.000 \\
\hline Banking online & 32.3 & 25.7 & 0.000 \\
Searching for jobs & 21.3 & 17.7 & 0.000 \\
Listening to the radio/viewing TV or movies & 19.8 & 19.1 & 0.451 \\
Trading stocks or bonds & 8.1 & 6.1 & 0.002 \\
Taking a course & 7.3 & 5.4 & 0.001 \\
Making phone calls & 3.2 & 4.4 & 0.005
\end{tabular}

*These figures are restricted to people who are Internet users. We have underlined the activities that people with disabilities are more likely to perform at a statistically significant level than individuals without disabilities. 


\section{REFERENCES}

Anderson, R.H., T.K. Bikson, S.A. Law, and B.M. Mitchell. 1995. Universal Access to E-Mail - Feasability and Societal Implications. Santa Monica, Calif: RAND.

Bowker, Natilene, and Keith Tuffin. 2002. "Disability Discourses for Online Identities." Disability and Society 17:327-344.

Bradley, Natalie, and William Poppen. 2003. "Assistive Technology, Computers and Internet May Decrease Sense of Isolation fo Homebound Elderly and Disabled Persons." Technology and Disability 15:19-25.

Cook, Judith A., Genevieve Fitzgibbon, Drew Batteiger, Dennis D. Grey, Sylvia Caras, Howard Dansky, and Frances Priester. 2005. "Information Technology Attitudes and Behaviors among Individuals with Psychiatric Disabilities Who Use the Internet: Results of a Web-Based Survey." Disability Studies Quarterly 25.

D'Amour, Donna. 2004. "Technology Upgrade Boosts Access for Blind Canadians." in Reading Today.

DiMaggio, Paul, Eszter Hargittai, Coral Celeste, and Steven Shafer. 2004a. "Digital Inequality: From Unequal Access to Differentiated Use." Pp. 355-400 in Social

Inequality, edited by Kathryn Neckerman. New York: Russell Sage Foundation.

—. 2004b. "Digital Inequality: From Unequal Access to Differentiated Use." in Social Inequality, edited by Kathryn Neckerman. New York: Russell Sage Foundation.

Drainoni, Mari-Lynn, Bethlyn Houlihan, Steve Williams, Mark Vedrani, David Esch, Elizabeth Lee-Hood, and Cheryl Weiner. 2004. "Patterns of Internet Use by Persons with Spinal Cord Injuries and Relationship to Health-Related Quality of Life." Archives of Physical and Medical Rehabilitation 85:1872-1879.

Finn, Jerry. 1999. "An Exploration of Helping Processes in an Online Self-Help Group Focusing on Issues of Disability." Health and Social Work 24:220-231.

Goffman, Erving. 1963. Stigma; notes on the management of spoiled identity. Englewood Cliffs N J: Prentice-Hall.

Goggin, Gerard, and Christopher Newell. 2003. Digital disability : the social construction of disability in new media. Lanham: Rowman \& Littlefield.

Gordon, Beth Omansky, and Karen E. Rosenblum. 2001. "Bringing Disability into the Sociological Frame: A Comparison of Disability with Race, Sex and Sexual Orientation Statuses." Disability and Society 16:5-19.

Grimaldi, Caroline, and Tanya Goette. 1999. "The Internet and the Independence of Individuals with Disabilities." Internet Research 9:272-279.

Guo, Baorong, John C. Bricout, and Jin Huang. 2005. "A Common Open Space or A Digital Divide? A Social Model Perspective on the Online Disability Community in China." Disability and Society 20:49-66.

Hargittai, Eszter. 2003. "The Digital Divide and What To Do About It." Pp. 822-839 in The New Economy Handbook, edited by Derek C. Jones. San Diego, Calif: Academic Press.

Kaye, H. Stephen. 2000. "Computer and Internet Use Among People with Disabilities." Washington, D.C.: U.S. Department of Education, National Institute on Disability and Rehabilitation Research.

Lenhart, Amanda, John Horrigan, Katherine Allen, Angie Boyce, Mary Madden, and Erin O'Grady. 2003. "The Ever-Shifting Internet Population: A New Look at 
Internet Access and the Digital Divide." Washington, D.C.: The Pew Internet and American Life Project.

Magnusson, Lennart, Elizabeth Hanson, and Martin Borg. 2004. "A Literature Review Study of Information and Communication Technology as a Support for Frail Older People Living at Home and Their Family Carers." Technology and Disability 16:223-235.

Mann, William C., Patricia Belchoir, Machiko R. Tomita, and Bryan J. Kemp. 2005. "Computer Use by Middle-Aged and Older Adults with Disabilities." Technology and Disability 17:1-9.

Margolis, Michael, and David Resnick. 2000. Politics as Usual: The Cyberspace "Revolution". Thousand Oaks: Sage Publications.

National Council on Disabilities. 1998. "Access to Multimedia Technology by People with Sensory Disabilities." Washington, D.C.: National Council on Disabilities.

National Council on Disability. 2003. "When the Americans with Disabilities Act Goes Online: Application of the ADA to the Internet and the Worldwide Web." Washington, D.C.: National Council on Disability.

NCDDR. 2000. "Survey 2000." Washington, DC: USED Publications.

Norris, P. 2001. Digital Divide: Civic Engagement, Information Poverty and the Internet in Democratic Societies. New York: Cambridge University Press.

NTIA. 2000. "Falling Through the Net: Toward Digital Inclusion." Washington, D.C.: U.S. Department of Commerce, Economics and Statistics Administration.

—. 2002. "A Nation Online: How Americans Are Expanding Their Use of the Internet." Washington, D.C.: NTIA, U.S. Department of Commerce, Economics and Statistics Administration.

Rizzo, Louis, J. Michael Brick, and Inho Park. 2004. "A Minimally Intrusive Method for Sampling Persons in Random Digit Dial Surveys." Public Opinion Quarterly 68:267-274.

Rushkoff, Douglas. 1996. Media virus! : hidden agendas in popular culture. New York: Ballantine Books.

Schwartz, Edward. 1996. Netactivism: How Citizens Use the Internet. Sebastopol, CA: Songline Studios.

Seymour, Wendy, and Deborah Lupton. 2004. "Holding the Line Online: Exploring Wired Relationships for People with Disabilities." Disability and Society 19:291305.

Smith, Tom W. 1979. "Sex and the GSS - Nonresponse Differences." Methodological Report 9.

Solomon, Karen. 2000. "Disability Divide." in The Standard.

Stephandis, Constantine, and Pier Luigi Emiliani. 1999. "'Connecting" to the Information Society: A European Perspective." Technology and Disability 10:21-44.

Sunstein, Cass. 2001. Republic.com. Princeton: Princeton University Press.

van Dijk, Jan A.G.M. 2005. The Deepening Divide. London: Sage Publications. Warschauer, M. 2003. Technology and Social Inclusion. Cambridge, Mass: MIT Press. World Wide Web Consortium. 2004. "How People with Disabilities Use the Web." in W3C Working Draft, 10 December 2004: World Wide Web Consortium. 